NBER WORKING PAPER SERIES

\begin{abstract}
ASSET MARKETS, TARIFFS, AND POLITICAL RISK
\end{abstract}

Alan C. Stockman

Harris Dellas

Working Paper No. 1413

NATIONAL BUREAU OF ECONOMIC RESEARCH

1050 Massachusetts Avenue

Cambridge, MA 02138

August 1984

Stockman gratefully acknowledges research support from the National Science Foundation, grant number SES-8309576, and helpful comments from Richard Cornes, Hans Genberg, Henryk Kierzkowski, and Alexander Swoboda, none of whom should be implicated in the results. The research reported here is part of the NBER's research program in International studies. Any opinions expressed are those of the authors and not those of the National Bureau of Economic Research. 
Asset Markets, Tariffs, and Political Risk

\section{$\underline{\text { ABSTRACT }}$}

The paper examines a simple model in which exogenous political risk creates uncertainty about tariffs. The model predicts a relation between consumption and tariffs that differs radically from that implied by models without asset markets or political risk. Given the probability distribution of tariffs, domestic consumption and utility (ex post) are lower in states of the world with a domestic tariff and no foreign tariff than with a foreign tariff and no domestic tariff. This conclusion emerges despite the fact that the opposite would be obtained in the absence of asset markets. So economists should not be surprised if observed relations between consumption and tariffs differ from the predictions of static theory in either time-series or cross-sections.

Alan C. Stockman Department of Economics University of Rochester Rochester, NY 14627 (716) $275-4427$
Harris Dellas Department of Economics Boston College. Chestnut Hi11, MA 02167 (617) 552-3670 


\title{
Asset Markets, Tariffs, and Political Risk
}

\author{
Alan C. Stockman
}

Harris Dellas

\section{Introduction}

The theory of protection has been developed in nonstochastic models without international asset trade. Extensions of the theory of international trade to encompass uncertainty have focused primarily on stochastic technologies or stochastic prices faced by a small economy. Helpman and Razin (1978) and Pomery (1984) survey and develop some of these models. However, little work has been done on the effects of uncertainty that results from the political process, even though that process is often thought to be an important source of uncertainty. Political risk has been cited, for example, as a reason for segmentation of international capital markets (see the survey by Adler and Dumas, 1983) and as an important factor affecting international direct investment.

This paper examines a simple model in which exogenous political risk creates uncertainty about tariffs. We focus on the effects of this risk on optimal portfolio allocation, and the implications of asset market trade for resource allocation and ex post consumption and utility. We show that in a world with political risk, a tariff that increases consumption when no assets can be traded decreases ex post consumption and utility in the presence of complete asset markets. We present a model of a two-country world with exogenous, random tariffs. Households trade in asset markets, and choose optimal protfolios that depend on the stochastic properties of these random government policies. We show that, given the probability distribution of 
tariffs, domestic consumption and utility are lower in states of the world with a domestic tariff than in states with a foreign tariff. In fact, domestic consumption in states with a foreign tariff is higher than that with no tariffs. Our model, therefore, predicts a relationship between consumption and tariffs that differs radically from the relations implied by models that ignore asset markets.

\section{A simple Random Tariffs Model}

Consider a world of 2 countries, 2 goods that are endowments to the countries, and 4 states of the world. In state of the world 0 , there are no tariffs. In state of the world 1 , the domestic country imposes a tariff at rate $\tau$. In state 2 , the foreign (but not the domestic) country imposes a tariff at the same rate $\tau$. In state of the world 3 , both countries impose tariffs at rate $\tau$. Assume that all tariff revenues are refunded to consumers in the country imposing the tariff, in a lump-sum manner. Assume that states 1 and 2 have equal probabilities, and denote the probability of any state by $\pi_{i}$. Call the two goods $X$ and $Y$. Let $\bar{X}$ and $\bar{Y}$ denote endowments of $X$ and $Y$ in the home country. Let $\overline{\mathrm{X}}^{*}$ and $\overline{\mathrm{Y}}^{*}$ denote foreign endowments, and assume that $\bar{X}=\bar{Y}^{*}$ and $\bar{Y}=\bar{X}^{*}$, and that $\bar{X}$ is sufficiently large relative to $\bar{Y}$ that the home country will always be an exporter of $X$ and an importer of $Y$, in the cases discussed here. We interpret the random tariffs as resulting from uncertainty in the political process.

Assume that there is a representative consumer in each country and that tastes are identical across countries. Trade occurs because of different endowments. Moreover, assume that the function $U(x, y)=U(y, x)$, for all $x, y$, and that $\mathrm{U}_{12}=0$. Let the representative consumer choose his holdings of Arrow-Debreu securities (claims to a unit of good $i$ in state $j$ ) to maximize 
$\sum_{i=\theta}^{3} \pi_{i} \mathrm{U}\left(\mathrm{x}_{i}, \mathrm{y}_{i}\right)$

subject to

$$
\begin{aligned}
0= & \sum_{i=0}^{3} p_{i}\left(\bar{X}-x_{i}\right)+\sum_{i=0,2} q_{i}\left(\bar{Y}-y_{i}\right)+\sum_{i=1,3} q_{i}(1+\tau)\left(\bar{Y}-y_{i}\right) \\
& -\sum_{i=1,3} q_{i} \overline{\left(\bar{Y}-y_{i}\right)}
\end{aligned}
$$

for the individual in the home country and

$$
\begin{aligned}
0= & \sum_{i=0}^{3} q_{i}\left(\bar{Y}^{*}-y_{i}^{*}\right)+\sum_{i=0,1} p_{i}\left(\bar{X}^{*}-x_{i}^{*}\right)+\sum_{i=2,3} p_{i}(1+\tau)\left(\bar{X}^{-*}-x_{i}^{*}\right) \\
& -\sum_{i=2,3} \overline{\left(\bar{X}^{*}-x_{i}^{*}\right)}
\end{aligned}
$$

for the individual in the foreign country. In (2) and (3), $x_{i}^{*}$ denotes foreign consumption of $\mathrm{X}, \mathrm{y}_{i}^{*}$ foreign consumption of $\mathrm{Y}, \mathrm{p}_{i}$ the relative price of $X$ in state $i$ in terms of $X$ in state $0, q_{i}$ the relative price of $Y$ in state $i$ in terms of $Y$ in state 0 , and a bar over a variable in parentheses indicates that this stands for an aggregate value of a variable, taken as given by the individual in his utility-maximization. The interpretation of (2) and (3) is easy. Consider (2). The first term on the right-hand-side shows the value of exports of $X$ in state $i$ (measured in units of $X$ in state 0 ) added together. These exports are just the state-dependent payments that a person in country one commits himself to by selling Arrow-Debreu securities. The second term shows imports in the two states in which the home country's government does not impose a tariff. The third term shows imports in the two states in which there is a home tariff, and the final term shows that the tariff revenue is refunded to people in country one. The bar indicates that the representative 
consumer takes this refund as given when he chooses his portfolio, since it depends on the aggregate choices in the economy over which he has no control.

Our symmetry assumptions imply

$$
\begin{aligned}
& \mathrm{q}_{0}=1, \mathrm{q}_{3}=\mathrm{p}_{3}, \mathrm{q}_{2}=\mathrm{p}_{1}, \mathrm{q}_{1}=\mathrm{p}_{2}, \\
& \mathrm{x}_{0}=\mathrm{y}_{0}=\mathrm{x}_{0}^{*}=\mathrm{y}_{0}^{*}, \mathrm{x}_{3}=\mathrm{y}_{3}^{*}, \\
& \mathrm{y}_{3}=\mathrm{x}_{3}^{*}, \mathrm{x}_{1}=\mathrm{y}_{2}^{*}, \mathrm{y}_{1}=\mathrm{x}_{2}^{*}, \mathrm{x}_{2}=\mathrm{y}_{1}^{*}, \text { and } \mathrm{y}_{2}=\mathrm{x}_{1}^{*} .
\end{aligned}
$$

The first-order conditions for the maximization problem in the home country yield

$$
\begin{aligned}
& \pi_{0} U_{1}\left(x_{0}, y_{0}\right)=\pi_{0} U_{2}\left(x_{0}, y_{0}\right)=\lambda \\
& \frac{\pi_{2}}{p_{2}} U_{1}\left(x_{2}, y_{2}\right)=\frac{\pi_{2}}{q_{2}} U_{2}\left(x_{2}, y_{2}\right)=\lambda \\
& \pi_{1} U_{1}\left(x_{1}, y_{1}\right)=\lambda p_{1}, \pi_{1} U_{2}\left(x_{1}, y_{1}\right)=\lambda q_{1}(1+\tau) \\
& \pi_{3} U_{1}\left(x_{3}, y_{3}\right)=\lambda p_{3}, \pi_{3} U_{2}\left(x_{3}, y_{3}\right)=\lambda q_{3}(1+\tau) .
\end{aligned}
$$

From the symmetry conditions (4), there are only three independent relative prices, $p_{1}, p_{2}$, and $p_{3}$. The equilibrium conditions

$$
\begin{aligned}
& x^{W}=x_{i}+x_{i}^{*} \\
& y^{W}=y_{i}+y_{i}^{*}
\end{aligned}
$$

(where $X^{W} \equiv \bar{X}+\vec{X}^{*}, Y^{W} \equiv \bar{Y}+\vec{Y}^{*}$ ) for all $i$, together with (4), imply that

$$
x_{0}=y_{0}=x_{0}^{*}=y_{0}^{*}=\frac{x^{w}}{2}
$$

Intuitively, in state 0 the two countries are identical in all respects except the particular goods in which they are endowed. But the endowments have equal value and the countries pool their goods in state 0. 
Using the first order conditions ( 8 ) and the symmetry conditions (4) and (9) in state 3 , it is seen that

$$
\frac{\mathrm{u}_{1}\left(\mathrm{x}_{3}, \mathrm{x}^{\mathrm{w}}-\mathrm{x}_{3}\right)}{\mathrm{u}_{2}\left(\mathrm{x}_{3}, \mathrm{x}^{\mathrm{w}}-\mathrm{x}_{3}\right)}=\frac{1}{1+\tau}
$$

determines $x_{3}$. (Note that $x_{3}^{*}$ is then determined from (9), and that (4) implies $y_{3}=x_{3}^{*}$ and $x_{3}=y_{3}^{*}$ )

We have only to solve for prices and equilibrium allocations in states 1 and 2. The equilibrium conditions (9) and (10), symmetry conditions (4), and the first-order conditions (6) and (7) give us

$$
\begin{aligned}
& x^{W}=x_{1}+y_{2} \\
& x^{W}=x_{2}+y_{1} \\
& U_{1}\left(x_{1}, y_{1}\right)=U_{2}\left(x_{2}, y_{2}\right) \\
& U_{2}\left(x_{1}, y_{1}\right)=U_{1}\left(x_{2}, y_{2}\right)(1+\tau) .
\end{aligned}
$$

But symmetry of the utility function implies

$$
\mathrm{U}_{1}\left(\mathrm{x}_{1}, \mathrm{x}^{\mathrm{w}}-\mathrm{x}_{2}\right)=\mathrm{U}_{2}\left(\mathrm{x}^{\mathrm{w}}-\mathrm{x}_{2}, \mathrm{x}_{1}\right)
$$

Then, by (15), (17), and (4),

$$
x_{1}=y_{2}=\frac{x^{w}}{2}
$$

According to (18), the goods not subjected to tariffs are consumed in the same quantities as they would be with free trade. ${ }^{1}$ (16) and (17) imply 


$$
\begin{aligned}
& 1+\tau=\frac{U_{2}\left(\frac{x^{w}}{2}, x^{w}-x_{2}\right)}{U_{1}\left(x_{2}, \frac{x^{w}}{2}\right)}=\frac{U_{1}\left(x^{w}-x_{2}, \frac{x^{w}}{2}\right)}{U_{1}\left(x_{2}, \frac{x^{w}}{2}\right)} \equiv h\left(x_{2}\right), \\
& x_{2}=h^{-1}(1+\tau) .
\end{aligned}
$$

Notice that (19) implies $x_{2}>\frac{x^{w}}{2}$, and $y_{1}<\frac{x^{W}}{2}$. The domestic country obtains higher consumption and higher utility when state 2 occurs than when state 1 occurs, i.e. the domestic country is better off when the foreign country imposes a tariff. In fact, the domestic country is better off when the foreign country imposes a tariff than with free trade. And the domestic country is better off with free trade than if it imposes a tarif $\bar{f}$. The domestic country prefers state 2 (a foreign tariff) to state 0 (no tariffs) to state 3 (tariffs in both countries) to state 1 (a domestic country tariff). Whatever the foreign country does, the domestic country is better of $f$ without a tariff, and whatever the domestic country does, it is better of $f$ if the foreign country imposes a tariff. (In each case, the term "better off" obviously refers to ex post consumption and utility, as ex ante consumption and utility are identical across countries in our example.) The ranking of states in this model is very different from the standard trade model or in an uncertainty model without asset markets.

As an example, let the utility function be $\ln (x)+\ln (y)$. Then

$$
\begin{aligned}
& x_{1}=y_{2}=\frac{x^{W}}{2} \\
& x_{2}=\frac{1+\tau}{2+\tau} x^{W} \\
& y_{1}=\frac{1}{2+\tau} x^{w} \\
& p_{1}=q_{2}=\frac{\pi_{1}}{\pi_{0}}
\end{aligned}
$$

and 


$$
p_{2}=q_{1}=\left(\frac{1}{2}\right)\left(\frac{2+\tau}{1+\tau}\right) \frac{\pi_{1}}{\pi_{0}} .
$$

Notice that a tariff improves the terms of trade, e.g. in state 0 the terms of trade are unity while in state 1 the terms of trade are $(2+2 \tau) /(2+\tau)$. Despite the improvement in the terms of trade, consumption is lower, i.e. $x_{1}=x_{0}$ but $y_{1}<y_{0}$. The log utility function also leads to a simple comparison of consumption in the presence of asset trade and consumption in the standard trade model (without asset trade). In the absence of asset markets, domestic consumption in state 1 (with a domestic tariff) would be

$$
\begin{aligned}
& \tilde{x}_{1}=\frac{1+\tau}{2+\tau} x^{w} \\
& \tilde{y}_{1}=\frac{1}{2} x^{w}
\end{aligned}
$$

while if state 2 occurs,

$$
\begin{aligned}
& \widetilde{x}_{2}=\frac{1}{2} x^{\omega} \\
& \widetilde{y}_{2}=\frac{1}{2+\tau} x^{\omega} .
\end{aligned}
$$

Tildas over variables have been used to denote the solution in the absence of asset trades. Without asset trades, the domestic country clearly prefers state 1 to state 2 . Notice the relations between (26)-(27) and (21)-(23). Consumption in state 1 in the presence of asset trade is identical to consumption in state 2 in the absence of asset trade, and consumption in state 2 in the presence of asset trade is identical to consumption in state 1 without asset trade. So with this utility function, asset markets lead the country to attain the same consumption when the other country imposes a tariff as it would if it imposed a tariff in a world without asset trade. Also in this example, the effect of a tariff on the terms of trade is smaller with 
asset markets than without them. Without asset markets, the terms of trade in state 1 would be $(2+\tau) / 2$. (This is an increase from unity in state 0. ) With asset markets, the terms of trade in state 1 are

$$
\left.\frac{2+2 \tau}{2+\tau}=\frac{2+\tau}{2}\right]\left[1-\frac{\tau^{2}}{(\tau+2)^{2}}\right]<\frac{2+\tau}{2} \text {. }
$$

The symmetry conditions that we have assumed in this section are not important to the main idea, though they vastly simplify the solution. The important point is that individuals with access to asset markets attempt to insure against adverse states of nature. Optimal portfolios eliminate (in one sense) variations in wealth across states of nature, though they cannot eliminate substitution effects from variations in prices. Individuals who have "sold" their wealth gain in a good state to "buy" wealth that offsets a loss (the wealth effect of a fall in the terms of trade) in another state, face only substitution effects from tariffs. Since these substitution effects are associated with distorted prices when a home tariff is imposed, individuals are worse off in this case. On the other hand, when the other country imposes a tariff, there is a pure substitution effect that raises utility.

In Figure 1.a, the domestic country is shown in state 1. Figure 1.b shows the foreign country in state 1 . Points $A$ and $A \div$ show consumption levels that would occur in state 0 (no tariffs), while points $B$ and $B *$ show consumptions in state 1 in the presence of complete asset markets. The dashed line shows that the tariff has improved the domestic country's terms of trade, but the budget 1 ines rotate through points $C$ and $C *$ because of optimal asset trades. The domestic country consumes less with the domestic tariff, while the foreign country consumes more. Consumptions in state 2 are shown as $D$ and D*. 


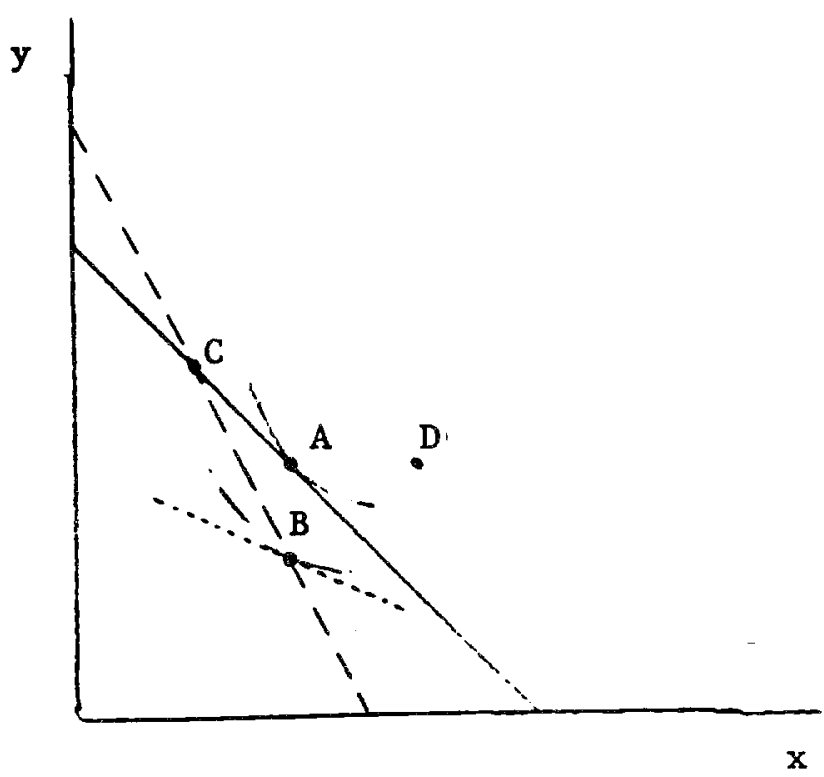

Figure 1.a

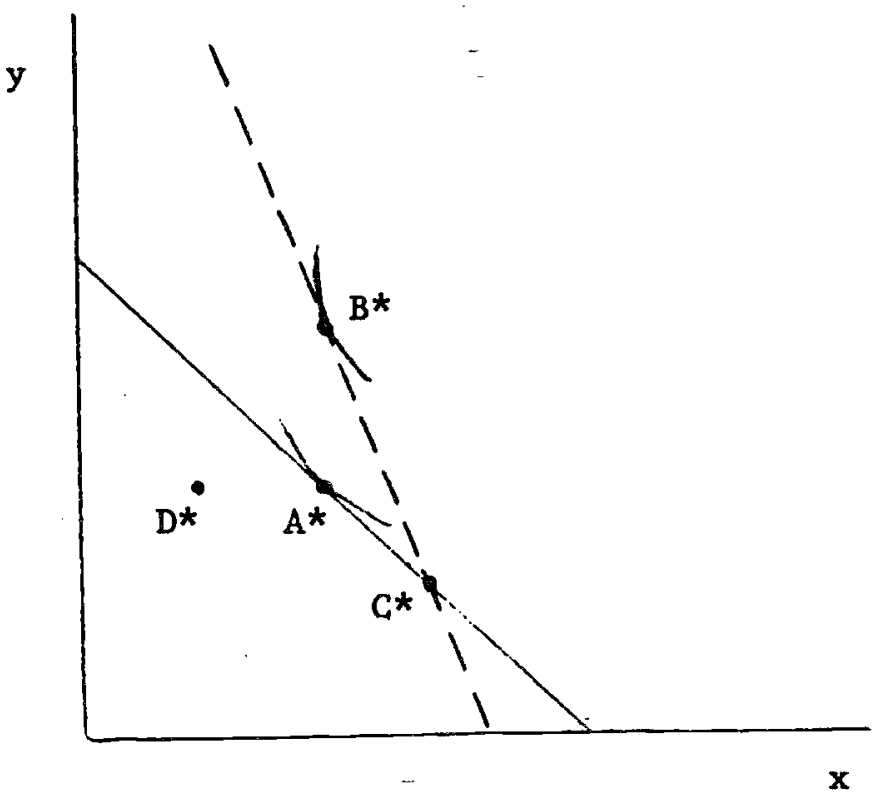

Figure 1.b

In the log-utility example, expected utility is unaffected by the ability to trade in asset markets. However, this conclusion does not generalize to other utility functions or to models with production. But the question arises as to why anyone would trade assets in the example. The answer is that if other people trade assets and you do not, then you will have lower expected utility. This occurs because you will obtain a positive income effect from a domestic tariff (making you better off if state 1 occurs) but you will receive a fall in income if there is a foreign tariff (state 2). These income differences are of equal magnitude (at given prices), so that concavity of your utility function guarantees you lower utility if you do not purchase the assets than if you do. Similarly, if no one else purchases assets, you can raise your expected utility by buying them.

\section{I. Tariff Probability and Size}


In the previous sections it was shown that when there is a complete set of asset markets and tariffs are the result of a political process with some randomness attached, optimal portfolio investment radically alters the covariation of consumption and tariffs. Instead of consuming more with a domestic tariff that improves the terms of trade, a country consumes less in states of the world in which it imposes a tariff, and consumes more in states in which the other country imposes a tariff.

We now investigate the effects of changes in the size of tariffs and the probabilities that they will be imposed. We show that, in our-example from section II, an industry in the domestic country has an incentive to lobby for tariff protection in the sense of a higher probability that the tariff will be imposed or a larger tariff.

In order to make the problem tractable in the absence of symmetry between the countries, assume that the utility functions of the representative individuals in the domestic and foreign countries are of the HARA class, which contain the quadratic, the constant relative risk-aversion, and constant absolute risk-aversion utility functions as special cases, which permit aggregation in fairly general circumstances, and which lead to simple relations between individual allocations and economy-wide allocations that have been called "sharing rules." (See Milne (1979), Rubinstein (1974), Grauer, Litzenberger, and Stehle (1976), and Dumas (1982)). The HARA utility function class is the class that has

$$
-\frac{\mathrm{U}_{1}}{\mathrm{U}_{11}}=\mathrm{A}+\mathrm{Bx}
$$

The utility functions that produce this result are 


$$
\begin{array}{ll}
U(C)=\frac{1}{B-1}(A+B C)^{\frac{B-1}{B}} & , B \neq 0,1 ; \\
U(C)=-A \exp \left(-\frac{C}{A}\right)^{-} & , B=0, A \neq 0 ; \\
U(C)=\ln (A+C) & , B=1 .
\end{array}
$$

We will assume throughout that the utility functions we work with are additive in the various goods consumed.

In each of the two countries, there is a representative individual who consumes both goods and receives endowments of each good. Assume that all individuals have an identical HARA utility function but that the representative person in the home country has the endowment $(\bar{X}, \bar{Y})$ while the representative person in the foreign country has the different endowment $\left(\bar{X}^{*}, \bar{Y}^{*}\right)$. Again let $\mathrm{X}$ be the domestic country's export good, assume there are four possible states of the world that differ only insofar as tariffs are concerned, as in the previous section. However, we drop the symmetry assumptions made in section II, e.g. we no longer require $\pi_{2}=\pi_{3}$ or $\tau=\tau \%$.

The representative individual in the domestic country maximizes (1) subject to (2). The representative individual in the foreign country has an analogous problem but with (a) a different endowment, (b) possibly a different tariff rate, and (c) tariffs imposed in states 2 and 3 rather than 1 and 3 .

Although each individual chooses eight assets (paying off two different goods in each of four states of the world) in the model, the HARA utility assumption can be used to solve the model by drastically reducing the dimensions. In particular, note that relative prices in the two countries of al1 state-indexed-goods are equal except when a tariff is imposed on one of the goods. Thinking of consumption of $X$ in state 0 as the numeraire, the marginal rates of substitution of $Y$ in state $0, X$ in state 1 , and $Y$ in state 2 (with $\mathrm{X}$ in state 0 ) are equal across countries. E.g. 


$$
\frac{\pi_{1}\left(A+B x_{1}\right)^{-1 / B}}{\pi_{0}\left(A+B x_{0}\right)^{-1 / B}}=\frac{\pi_{1}\left(A+B x_{1}^{*}\right)^{-1 / B}}{\pi_{0}\left(A+B x_{0}^{*}\right)^{-1 / B}}
$$

Consequent ly

$$
\frac{A+B x_{1}}{A+B x_{0}}=\frac{2 A+B X^{W}}{2 A+B X^{W}}
$$

where $X^{W}$ and $Y^{W}$ are total world endowments of $X$ and $Y$. The form of (30) is all that is needed for the simplifications. The assumptions that endowments are state-independent or that all parameters of utilities are equal across countries could be relaxed easily. (30) and its analogues from the other marginal rates of substitution mentioned above imply that one can define a number (independent of the state) $v$ such that

$$
\nu=\frac{A+B x_{0}}{2 A+B X^{W}}=\frac{A+B y_{0}}{2 A+B Y^{W}}=\frac{A+B x_{1}}{2 A+B X^{W}}=\frac{A+B y_{2}}{2 A+B Y^{W}}
$$

(31) and market-clearing conditions for these four state-indexed goods can be used to solve for $x_{0}, y_{0}, x_{0}^{*}, y_{0}^{*}, x_{1}, x_{1}^{*}, y_{2}$, and $y_{2}^{*}$ as functions of total world endowments and the parameter $\nu$.

Four goods remain: $Y$ in state $1, X$ in state 2 , and both $X$ and $Y$ in state 3. The relations between the marginal rates of substitution in the two countries between these goods and $X$ in state 0 yield

$$
\begin{aligned}
& \frac{A+B y_{1}}{A+B x_{0}}(1+\tau)^{B}=\frac{A+B y_{1}^{*}}{A+B x_{0}^{* *}} \\
& \frac{A+B x_{2}}{A+B x_{0}}=(1+\tau *) B \frac{A+B x_{2}^{*}}{A+B x_{0}^{* *}} \\
& \frac{A+B x_{3}^{*}}{A+B x_{0}}=(1+\tau *) \frac{A+B x_{3}^{*}}{A+B x_{0}}
\end{aligned}
$$




$$
\frac{A+B y_{3}}{A+B x_{0}} \cdot(1+\tau)^{B}=\frac{A+B y_{3}^{*}}{A+B x_{0}^{*}}
$$

The market-clearing conditions can be used with these four equations to solve for the remaining allocations. With state-independent endowments, it is obvious that $y_{1}=y_{3}$ and $x_{2}=x_{3}$. A little manipulation reveals that

$$
\begin{aligned}
& y_{1}=Y^{W}\left[1+\frac{1-v}{\nu}(1+\tau)^{B}\right]^{-1}-\frac{A}{B}=y_{3} \\
& x_{2}=\frac{B X^{W}+A\left[1-\frac{1-v}{\nu}(1-\tau *)^{-B}\right]}{B\left[1+\frac{1-\nu}{\nu}(1+\tau *)^{-B}\right]}=x_{3}
\end{aligned}
$$

With these allocations known as functions of $\nu$, one can calculate price functions (of $v$ ) directly from marginal rates of substitution. When these prices and allocations are substituted into the budget constraint, one can solve for $v$ as a function of endowments, the tariffs, the state-probabilities, and the parameters of utility. $\nu$ is a measure of relative wealths of the two countries.

The log-utility example of section II is obtained by setting $A=0$ and $B=1$, in which case

$$
\begin{aligned}
& x_{0}=x_{1}=v X^{w} \\
& y_{0}=y_{2}=v Y^{w} \\
& x_{2}=x_{3}=X^{\omega}\left[1+\frac{1-v}{v}(1+\tau *)^{-1}\right]^{-1} \\
& y_{1}=y_{3}=Y^{\omega}\left[1+\frac{1-v}{v}(1+\tau)\right]^{-1}
\end{aligned}
$$


Foreign consumptions can be obtained from these quantities-and the equilibrium conditions. Substituting into the conditions equating marginal rates of substitution with relative prices, we obtain

$$
\begin{aligned}
& q_{0}=\frac{X^{w}}{Y^{w}} \\
& p_{1}=\frac{\pi_{1}}{\pi_{0}}, \quad q_{1}=\frac{\pi_{1}}{\pi_{0}} \frac{X^{w}}{Y^{w}} \frac{1+\tau(1-\nu)}{1+\tau} \\
& p_{2}=\frac{\pi_{2}}{\pi_{0}} \frac{1+\tau \div n}{1+\tau *}, q_{2}=\frac{\pi_{2}}{\pi_{0}} \frac{X^{w}}{Y^{w}} \\
& p_{3}=\frac{\pi_{3}}{\pi_{0}} \frac{1+\tau * n}{1+\tau *}, q_{3}=\frac{\pi_{3}}{\pi_{0}} \frac{X^{w}}{Y^{w}} \frac{1+\tau(1-\nu)}{1+\tau}
\end{aligned}
$$

These expressions for prices still involve the parameter $\nu$ which is a measure of the relative wealth of the domestic country as compared to the foreign country, as is obvious from (31) and (38)-(41). $v$ depends on relative endowments of the two goods in each country (and in each state), as well as probabilities of tariffs and magnitudes of tariffs. If each country has no endowments of its import good $\left(\bar{Y}=\bar{X}^{-*}=0\right)$, then

$$
\nu=\frac{\pi_{0}+\pi_{1}+\frac{\pi_{2}+\pi_{3}}{1+\tau *}}{2-\frac{\tau}{1+\tau}\left(\pi_{1}+\pi_{3}\right)-\frac{\tau *}{1+\tau *}\left(\pi_{2}+\pi_{3}\right)} .
$$

It is obvious from (46) that $\frac{\mathrm{d} \nu}{\mathrm{d} \tau}>0$ and $\frac{\mathrm{d} \nu}{\mathrm{d} \tau^{*}}<0$ (to see the latter, note that $\nu * \equiv 1-\nu$ has a form symmetric to (46)). Thus, given the probabilities of each state of the world, the home country benefits from a higher home tariff 
and loses from a higher foreign tariff, even though, ex post, the home country prefers the state in which it does not have a tariff and in which the foreign country does. ${ }^{2}$ The existence of asset markets does not prevent domestic political pressure for higher tariffs in some states of the world.

Now consider domestic political pressure to alter the probability of a home tariff. It is obvious from (46) that an increase in $\pi_{1}$ offset by an equal fall in $\pi_{0}$, or an increase in $\pi_{3}$ offset by an equal fall in $\pi_{2}$, raises v. Thus there is an incentive for the home country to lobby for tariffs in a way that increases the probability of a tariff regardless of what the other country does.

\section{Conclusions}

The main conclusion of the paper is that, in a world with asset markets and political uncertainty, the observed relations between tariffs and consumption may differ radically from thos predicted by standard trade theory (without asset markets). In our example, domestic consumption of both imports and exports is higher when there is a foreign tariff (and no domestic tariff) than when there is a domestic tariff (and no foreign one). (This conclusion was obtained despite the fact that the tariffs are small enough to improve domestic welfare if no assets are traded.) Economists should not be surprised if observed relations between consumption and tariffs differ from the predictions of the standard trade theory in either time-series or crosssections.

In our example, a country prefers states of the world in which it does not impose a tariff and/or the foreign country does. However, a country is made better off by a higher probability of a domestic tariff, lower probability of a foreign tariff, and by a higher (conditional) domestic tariff 
and lower foreign tariff. From this standpoint, the optimal policy is "talkloudly but carry a small stick," presuming that anyone will believe the talk.

of course, assets are not likely to be priced in accordance with tariff probabilities that fail to reflect actual tariff frequencies (and sizes) over time. If imposing a tariff today leads asset markets to revise upward the probability that tariffs will also be imposed in the future, then there is an "investment" aspect to imposing a tariff. Part of the return from this investment can be captured by not imposing a tariff at some future date.

We have discussed a world with complete asset markets, and it would be useful to obtain some results when asset markets are more restricted. That would reduce the ability of individuals to insure, though some asset trades that cannot be made directly by individuals may be indirectly available through multinational corporations. We have also neglected all uncertainty except that due to the political process. Nor have we examined the intracountry redistributions of income between factors due to tariffs when asset trades are permitted. Finally, we have followed "standard" trade theory in treating tariffs as exogenous. We leave for future research the incorporation of domestic political equilibria and international trade negotiations into a model of tariffs with uncertainty and asset markets. 


\section{Footnotes}

(1) This is a consequence of the assumption that $U_{12}=0$. If $U_{12} \neq 0$ then $x_{1}$ and $x_{2}$ are given implicitly by

$$
\mathrm{U}_{1}\left(\mathrm{x}_{1}, 1-\mathrm{x}_{2}\right)=\mathrm{U}_{1}\left(1-\mathrm{x}_{1}, \mathrm{x}_{2}\right)
$$

and

$$
\mathrm{U}_{1}\left(\mathrm{x}_{2}, 1-\mathrm{x}_{1}\right)(1+\tau)=\mathrm{U}_{1}\left(1-\mathrm{x}_{2}, \mathrm{x}_{1}\right)
$$

and

$$
\mathrm{y}_{1}=\mathrm{x}_{2}, \mathrm{y}_{2}=\mathrm{x}_{1} \text {. }
$$

(2) The fact that $\nu \varepsilon[0,1]$ is used to see that $y_{1}$ is increasing in $\tau$. 


\section{References}

Adler, M. and B. Dumas (1983), "International portfolio choice and corporation finance: A synthesis," Journal of Finance, June, pp. 925-984.

Caves, R.E. and R.W. Jones (1977), World Trade and Payments, 2nd ed. (Little Brown, Boston).

Corden, W.M. (1971), The Theory of Protection (Oxford University Press, London ).

Dumas, B. (1982), "Sharing rules and equilibrium in a monetary economy" in Sornat and Stegs (eds.), Capital Markets and Inflation (Ballinger).

Fama, E. (1976), Foundations of Finance (Basic Books, New York).

Grauer, F.L.A., R.H. Litzenberger and R.E. Stehle (1976), "Sharing rules and equilibrium in an international capital market under uncertainty," Journal of Financial Economics, June, pp. 233-256.

Helpman, E. and A. Razin (1978), A Theory of International Trade Under Uncertainty (Academic Press, New York).

Milne, F. (1979), "Consumer preferences, linear demand functions, and aggregation in competitive asset markets," Review of Economic Studies, Ju1y, pp. 407-417.

Pomery, J. (1984), "Uncertainty in Trade Models," Chapter 9 in R. Jones and P. Kenen (eds.), Handbook of International Economics (North-Holland, Amsterdam).

Rubinstein, M. (1974), "An aggregation theorem for security markets," Journal of Financial Economics, September, pp. 225-244.

Stu1tz, R.M. (1981), "A model of international asset pricing," Journal of Financial Economics, December, pp. 383-406. 


\section{Appendix on Production}

Production can be incorporated into the model of section II without changing the nature of the results. Suppose the domestic economy has production opportunities described by

$$
F(\bar{X}, \bar{Y})=0
$$

or $\bar{Y}=f(\bar{X})$ with $f_{1}$ and $f_{11}$ negative. Similarly, let

$$
G\left(\vec{X}^{*}, \vec{Y}^{*}\right)=0
$$

describe the foreign country's production opportunities, and let $\overline{\mathrm{X}}^{*}=\mathrm{g}\left(\overline{\mathrm{Y}}^{*}\right)$, wigh $g_{1}$ and $g_{11}$ negative.

To maintain symmetry, assume that $F(X, Y)=G(Y, X)$ everywhere. Then $f$ and $g$ are identical functions: the two countries have different production opportunities, but each has the same opportunities for producing the other country's good. We continue to identify $X$ with the domestic country's export good. Symmetry implies

$$
\begin{aligned}
& \overrightarrow{\mathrm{X}}_{0}=\overrightarrow{\mathrm{Y}}_{0}^{*}, \overline{\mathrm{Y}}_{0}=\overrightarrow{\mathrm{X}}_{0}^{*} \\
& \overrightarrow{\mathrm{X}}_{3}=\overrightarrow{\mathrm{Y}}_{3}^{*}, \overrightarrow{\mathrm{Y}}_{3}=\overrightarrow{\mathrm{x}}_{3}^{*} \\
& \overrightarrow{\mathrm{x}}_{1}=\overrightarrow{\mathrm{Y}}_{2}^{*}, \overrightarrow{\mathrm{Y}}_{1}=\overrightarrow{\mathrm{X}}_{2}^{*} \\
& \overrightarrow{\mathrm{x}}_{2}=\overrightarrow{\mathrm{Y}}_{1}^{*}, \overline{\mathrm{Y}}_{2}=\overrightarrow{\mathrm{X}}_{1} .
\end{aligned}
$$

The additional first-order conditions associated with production decisions are, after using (4), 


$$
\begin{aligned}
& \bar{x}_{0}=f_{1}^{-1}(-1) \\
& \bar{x}_{1}=f_{1}^{-1}\left(-\frac{p_{1}}{p_{2}(1+\tau)}\right) \\
& \bar{x}_{2}=f_{1}^{-1}\left(-\frac{p_{2}}{p_{1}}\right) \\
& \bar{x}_{3}=f_{1}^{-1}\left(-\frac{1}{1+\tau}\right)
\end{aligned}
$$

where $f_{1}^{-1}$ is the inverse function of $f_{1}$. It is obvious from (50) that $\overline{\mathrm{X}}_{3}<\overline{\mathrm{X}}_{0}$, so $\overline{\mathrm{Y}}_{3}>\overline{\mathrm{Y}}_{0}$ and the domestic country produces less of its export good and more of its importable in state 3 than in state 0 .

In state $0,(11)$ is still the solution for consumptions, where production must now be indexed by state, and $\bar{x}_{0}$ is given in (50). Similarly, (12) with $x_{3}^{W}$ replacing $x^{W}$ gives consumption in state (3), where

$$
X_{3}^{W}=f_{1}^{-1}\left(-\frac{1}{1+\tau}\right)+f\left(f_{1}^{-1}\left(-\frac{1}{1+\tau}\right)\right)
$$

The first term in (51) comes from (50); the second term comes from (50) and the symmetry condition $\bar{Y}_{3}=\bar{X}_{3}^{*}$. If $U_{12}=0$ then (13)-(16) still hold with $X^{W}$ replaced by $x_{1}^{W}$ in (13) and by $x_{2}^{W}$ in (14). Then (18) holds with $x_{1}^{W}$ replacing $x^{w}$, and (19) with $X$ replaced by $x_{2}$. These state-dependent world production levels are given by

$$
x_{1}^{w}=f_{1}^{-1}\left(-\frac{p_{1}}{p_{2}(1+\tau)}\right)+f\left(f_{1}^{-1}\left(-\frac{p_{2}}{p_{1}}\right)\right)
$$

and

$$
x_{2}^{w}=f_{1}^{-1}\left(-\frac{p_{2}}{p_{1}}\right)+f\left(f_{1}^{-1}\left(-\frac{p_{1}}{p_{2}(1+\tau)}\right)\right)
$$

Then (53) and (19) imply

$$
x_{2}>\frac{x_{2}^{w}}{2}, y_{1}<\frac{x_{2}^{w}}{2}
$$


Thus consumption in state 1 is $\left(\frac{x_{1}^{W}}{2}, y_{1}<\frac{x_{2}^{W}}{2}\right)$ while consumption in state 2 is $\left(x_{2}>\frac{x_{2}^{W}}{2}, \frac{x_{1}^{W}}{2}\right)$. Given the symmetry of the utility function, this implies that domestic country prefers state 2 (foreign tariff) to state 1 (domestic tariff) as in the endowments model.

In the log-utility example from the previous section, we have

$$
\begin{aligned}
& x_{1}=y_{2}=x_{1}^{W} / 2 \\
& x_{2}=\left(\frac{1+\tau}{2+\tau}\right) x_{2}^{W} \\
& y_{1}=\left(\frac{1}{2+\tau}\right) x_{2}^{W} \\
& p_{1}=q_{2}=\left(\frac{\pi}{\pi_{0}}\right) \frac{x_{0}^{w}}{x_{1}^{W}} \\
& p_{2}=q_{1}=\left(\frac{1}{2}\right)\left(\frac{2+\tau}{1+\tau}\right)\left(\frac{\pi_{2}}{\pi_{0}}\right) \frac{x_{0}^{w}}{x_{1}^{W}} .
\end{aligned}
$$

We have not constructed an example with a closed-form solution for both productions and consumptions, but suppose the production function of the domestic country is

$$
F(\vec{X}, \vec{Y})=2 \ln \bar{X}+\ln \bar{Y} .
$$

Then $f(\bar{x})=x^{-2}, f_{1}^{-1}(z)=\left(-\frac{z}{2}\right)^{-1 / 3}$. Thus

$$
\begin{aligned}
& \bar{X}_{0}=\left(\frac{1}{2}\right)^{-1 / 3} \\
& \bar{Y}_{0}=\left(\frac{1}{2}\right)^{2 / 3}<x_{0} \\
& \bar{X}_{1}=\left(\frac{1}{2+\tau} \frac{x_{2}^{w}}{x_{1}^{W}}\right)^{-1 / 3}
\end{aligned}
$$




$$
\begin{aligned}
& \bar{Y}_{1}=\left(\frac{1}{2+\tau} \frac{X_{2}^{w}}{X_{1}^{w}}\right)^{2 / 3} \\
& \bar{X}_{2}=\left(\frac{1}{4} \frac{2+\tau}{1+\tau}\right)^{-1 / 3} \\
& \bar{Y}_{2}=\left(\frac{1}{4} \frac{2+\tau}{1+\tau} \frac{X_{1}}{X^{W}}\right)^{2 / 3} \\
& \bar{X}_{3}=\left(\frac{1}{2} \frac{1}{1+\tau}\right)^{-1 / 3} \\
& \bar{Y}_{3}=\left(\frac{1}{2} \frac{1}{1+\tau}\right)^{2 / 3} .
\end{aligned}
$$

World productions are $X_{1}^{W}=\bar{X}_{1}+\bar{y}_{2}, \quad X_{2}^{W}=\bar{X}_{2}+\bar{Y}_{1}$. A little manipulation verifies that

$$
\begin{aligned}
& \left.\mathrm{dX}_{1}^{\mathrm{w}}\right|_{\tau=0}=-\left(\frac{1}{2}\right)^{-1 / 3}<0 \text { and } \\
& \left.\mathrm{dX}_{2}^{\mathrm{W}}\right|_{\tau=0}=2^{4 / 3}-\left(\frac{1}{2}\right)^{2 / 3}>0
\end{aligned}
$$

so that, for a small tariff, $X_{1}^{W}>X_{0}^{w}>X_{1}^{W}$ and $Y_{1}^{W}>Y_{0}^{W}>Y_{2}^{W}$. Thus a domestic tariff increases domestic production of $Y$ and reduces foreign production of $Y$, with a net increase in world production of $Y$ and $a$ fall in world production of $X$. Looking back at (54)-(56), we see that domestic consumption in state 1 is $\left(\frac{X_{1}^{W}}{2}, \frac{X_{2}^{W}}{2+\tau}\right)$ while domestic consumption in state 2 is $\left(\frac{1+\tau}{2+\tau} x_{2}^{w}, \frac{x_{1}^{w}}{2}\right)$. The utility difference between states 1 and 2 is thus approximately $U_{2} \frac{\tau X_{2}^{W}}{2+\tau}$. This utility difference is thus larger the larger 
$x_{2}^{w}$. In particular, it is larger when resources can be moved between the two sectors than when production is fixed at $\left(\overline{\mathrm{X}}_{0}, \overline{\mathrm{Y}}_{0}\right)$. Adding production to the model reinforces the results of section II because the tariff distorts production in the country in which it is imposed. 